\title{
Modelos de financiamiento al desarrollo para la industrialización del sector agrícola. El caso de la industria agroquímica en México y la empresa estatal Guanos y Fertilizantes (1943-1974)
}

Financing models to development for the industrialization of the agricultural sector. The case of agrochemical industry in Mexico and the state company "Guanos y Fertilizantes" (1943-1974)

\author{
Natalia Vargas Escobar \\ División de Estudios de Posgrado, Facultad de Economía Universidad Nacional \\ Autónoma de México (UNAM) \\ http://orcid.org/0000-0003-0049-1850 \\ nataliave@economia.unam.mx \\ Federico Andrés Stezano Pérez \\ Centro de Investigaciones Económicas, Administrativas y Sociales del Instituto \\ Politécnico Nacional (CIECAS-IPN), México \\ http://orcid.org/0000-0001-5450-6339 \\ fstezano@gmail.com
}

Fecha de recepción: 24 de septiembre de 2015 Fecha de aceptación: 03 de noviembre de 2015

Sugerencia de citación: Vargas, N. y Stezano, F. (2016). Modelos de financiamiento al desarrollo para la industrialización del sector agrícola. El caso de la industria agroquímica en México y la empresa estatal Guanos y Fertilizantes (1943-1974). tiempo\&economía, 3(1), 59-82, doi: http://dx.doi.org/10.21789/24222704.1095 


\title{
Resumen
}

Este artículo se propone analizar la trascendencia del modelo financiero como factor determinante de las implicaciones entre el sector agrícola y el Estado. Tal propuesta toma como referentes empíricos la trayectoria del financiamiento a la industria agroquímica en México y el caso de la creación y expansión de la industria fertilizante, a través de la retrospectiva histórica de la empresa Guanos y Fertilizantes de México (Guanomex). El artículo muestra que una iniciativa como Guanomex solo fue históricamente viable por la presencia de la intervención productiva institucionalizada del Estado a la actividad industrial. Esta intervención estatal toma en México la forma de banca de desarrollo: Nacional Financiera, S.A. (Nafin). Nafin es el actor protagónico que hace posible la creación, el desarrollo y consolidación de Guanomex. Para la construcción del estudio de caso, el trabajo se apoya en evidencia empírica novedosa: fuentes primarias de Nafin y del Export Import Bank de Estados Unidos, agencia pública estadounidense que autorizó, a través de negociaciones con Nafin, la mayor parte de fondos para la industrialización de la producción de fertilizantes en México. El trabajo busca enfatizar especialmente el modelo financiero como factor explicativo de las formas específicas en que se relacionan agricultura y Estado. Esta implicación, discernida desde la intervención financiera, no solo da cuenta de la composición y estructura de la industria agroquímica en México, sino que es también indicativa de la organización, autonomía y, en general, preponderancia del Estado en la configuración sectorial del desarrollo económico. La periodización y el recorte temporal propuestos en este análisis se guían por esta mutua determinación.

Palabras clave: Empresa pública, vínculo agricultura-Estado, capital público externo, repertorios nacionales de gestión y asignación del ahorro.

Códigos JEL: N01, N26, N56, N86

\begin{abstract}
This research paper analyzes the significance of financial model as a determinant factor of the relationships between the agriculture sector and the state. Our approach uses, as empirical reference, the trajectory of financing the agrochemical industry in Mexico and the case of the creation and expansion of the fertilizer industry through a historical retrospective of the company Guanos y Fertilizantes de México (Guanomex). This paper also shows how an initiative such as Guanomex would only be historically feasible with the prerequisite of an institutionalized intervention of the state in the industrial activity. This intervention in Mexico took the form of a national development bank: Nacional Financiera, S.A. (Nafin). Nafin is the main agent that makes possible the creation, development and consolidation of Guanomex. For the construction of the case study, our work is based on new empirical evidence: primary sources from Nafin and Export Import Bank of the United States, a public agency from EUA which, through negotiations with Nafin, authorized most funds for the industrialization of fertilizer production in Mexico. Finally, our paper seeks to emphasize the financial model as an explanatory factor of the specific ways in which agriculture and state are related. This implication, discerned from the financial assistance, not only realizes the
\end{abstract}


composition and structure of the agrochemical industry in Mexico, but is also indicative of the organization, autonomy and overall dominance of the state in sectorial shaping of the economic development. Periodization and the temporary selection proposed in this analysis is guided by this mutual determination.

Keywords: Public companies, agriculture-state links, external public capital, national varieties for management and allocation of savings and investment

JEL Codes: N01, N26, N56, N86 


\section{Introducción}

El presente artículo aborda la experiencia de creación y expansión de la industria fertilizante en el curso del proceso de la industrialización agrícola en México a partir de la creación de la empresa estatal Guanos y Fertilizantes de México (Guanomex).

La iniciativa de Guanomex muestra un caso de desarrollo industrial que solo fue históricamente viable con el prerrequisito de la intervención institucionalizada del Estado a la actividad industrial. El estudio de caso muestra cómo la intervención de la banca nacional de desarrollo (Nacional Financiera, S.A., Nafin) fue central: desde la ideación de la empresa hasta la canalización de fondos externos como primera fuente de fondos de la industria agroquímica nacional.

De esta forma, la temática de este trabajo se centra en las relaciones entre agricultura y Estado, comprendidas como concreciones históricas de un proceso de: (i) formación de un ámbito distintivo para gestionar y administrar el orden en un conjunto social y (ii) organización de un esquema capitalista de tipo industrial.

Esta es una interpretación común y altamente difundida, fundamentada en la argumentación de Weber (2003 [1905]) en La ética protestante y el espíritu del capitalismo: el orden racional del trabajo (y especialmente del trabajo industrial) permite el discernimiento entre bienes familiares y activos industriales. La difusión e intensidad de la forma económica capitalista fomentaron el establecimiento de una legalidad extendida, reconocida, y también de estatutos previstos para la gestión administrativa.

A partir de este argumento es posible plantear el supuesto central que articula este trabajo: así como una forma estatal (como el ámbito de gestión de la autoridad) puede emerger de manera diferenciada en distintos períodos según se desenvuelvan y adecuen sus propiedades (legitimidad, organización, autonomía, capacidad), también puede modificarse la forma económica capitalista. En tal sentido, puede sostenerse que no existe un sistema capitalista acabado.

Así, en torno al estudio de caso analizado en este trabajo, por ejemplo, se encuentra la coexistencia en un mismo período cronológico de fases de modernización industrial (fomentadas por la forma estatal y por una infraestructura de bancos privados) y formas de organización del trabajo aún definidas por el esquema de unidades productivas del tipo hacienda o núcleos familiares caracterizados por la agricultura de subsistencia. Igualmente puede detectarse en otro período histórico la presencia simultánea de accesos ampliados a la actividad productiva y al bienestar con fuertes rezagos en los procesos endógenos de aprendizaje tecnológico y generación de conocimiento. Esto muestra que no es posible ubicar un punto culminante para la organización económica capitalista y la forma estatal.

Con este encuadre analítico, este artículo se plantea como objetivo discernir, tipificar y periodizar las formas en que la actividad, el ámbito y sector productivo y los agentes de la agricultura se afectan, $y$, a su vez, condicionan la infraestructura administrativa estatal. Desde esta perspectiva se hace visible y manifiesto un proceso histórico que, estudiado desde otro encuadre analítico, sería completamente distinto. 
Los tipos de vinculación agricultura-Estado desde la independencia nacional y hasta el inicio del período abordado en este trabajo (1932) muestran tres fases distintivas: (i) desde 1810 y hasta la restauración de la República en 1867 se registraron rendimientos decrecientes de la agricultura latifundista (i.e., forma social y productiva de la hacienda); (ii) desde 1877 y hasta la Revolución Mexicana se despliega un Estado facilitador del crecimiento exportador derivado de la demanda creciente de materias primas de los países industriales y de una mayor integración de un mercado interno, hechos que aumentaron la comercialización de la agricultura y que derivaron en formas de concentración de la propiedad; y (iii) a partir de la Revolución no se alteró el andamiaje productivo, ni la composición de los grupos económicos prominentes, prevaleciendo hasta 1932 una forma estatal activa en cuanto a legislaciones y reformas, pero pasiva en términos de planeación e intervención en la estructura económica y productiva (Vargas, 2013).

A partir del referente empírico de la empresa Guanomex, este trabajo revisa los términos en que se planteó la organización estatal al financiamiento del desarrollo. Esta iniciativa, como se detalla seguidamente, adopta una trayectoria concretada desde la intervención pública financiera de Nafin. Guanomex se establece en 1943 como propiedad de la banca estatal de desarrollo Nafin. Una primera inflexión en la fase de despegue de la empresa fue el año 1948, cuando se amplían sus actividades de producción y distribución de fertilizantes químicos de Guanomex y se da la primera autorización de crédito a la industria agroquímica mexicana por parte del Export Import Bank de Estados Unidos (Exim) vía Nafin.

Desde finales de la década de 1940 y hasta finales de la de 1960, Guanomex fue no solo el principal abastecedor de fertilizantes para el sector agrícola nacional sino ante todo el principal agente en la planeación estratégica, la investigación científica y la regulación legalnormativa del sector agroquímico en México.

Así como se transformaron las relaciones entre el sector agrícola y el Estado con la creación de Guanomex, también durante este proceso se reajustó el proceso de diversificación de la propiedad en la industria agroquímica. En esta fase de desarrollo del sector se da un proceso de privatización en la producción de fertilizantes, al que le sigue una trayectoria de renacionalización de la industria que transforma a Guanomex en la nueva empresa Fertilizantes de México (Fertimex) como empresa paraestatal hacia la segunda mitad de la década de 1970. Sin embargo, la reestatización de la industria de fertilizantes apela a lógicas muy diferentes en relación con la creación original de Guanomex.

Las fuentes primarias utilizadas para la revisión del estudio de caso tienen dos orígenes principales: (i) los informes anuales de Nafin del período y (ii) memorandos a la Junta Directiva de Exim elaborados por sus asesores respecto a solicitudes de Nafin. Estas fuentes, ante la ausencia total de trabajos de investigación sistemática sobre Guanomex, brindan una información central en la conformación del referente empírico.

Este artículo adopta la siguiente estructura. La primera sección se consagra al planteo de una reformulación teórica de la implicación del proceso de formación estatal y desarrollo agrícola, ubicando al financiamiento como factor determinante del proceso de desenvolvimiento económico guiado por la oferta. Las siguientes secciones abordan la temática de los fertilizantes y el cambio tecnológico en la agricultura; los antecedentes de la instauración de Guanomex;

tiempo\&economía Vol. 3 N 1 - I semestre de 2016 
su desarrollo, trayectoria y transformación histórica de Guanos y Fertilizantes de México. La sección final concluye respecto a las características del desarrollo de las formas estatales y sus implicaciones sobre el desarrollo económico y productivo a la luz del estudio de caso analizado.

\section{Reformulación teórica del proceso de formación estatal y desarrollo agrícola}

Esta sección desarrolla un esquema centrado en la forma en que el Estado (de manera específica, su infraestructura para intervenir en la economía nacional) y el sector agrícola se relacionan y afectan mutuamente. Este esquema define el marco analítico de la concreción histórica de la experiencia de Guanomex y, a la vez, justifica la relevancia histórica de esta iniciativa al destacar la relación recíproca entre la constitución de un sector agrícola industrializado y el robustecimiento de la capacidad, autonomía y legitimidad de la forma estatal implicada.

El argumento parte del supuesto que en cuanto se establece una estructura de industrialización agrícola, la plataforma estatal se fortalece. E igualmente, que cuando el Estado pierde control sobre el patrón en que se desarrolla el sector agroindustrial (en cuanto ámbito de gestión de la estructura de una economía nacional) pierde centralidad, autonomía y capacidad (Vargas, 2013).

La conformación de un esquema de asignación y distribución de fondos a las actividades económicas estratégicas es una acción básica para la viabilidad histórica de un proceso de desarrollo nacional. Estas son acciones orientadas a solventar dos exigencias decisivas para la continuidad de la forma estatal: la legitimidad interna y la integración externa. Los procesos asociados a cada uno de estos dos imperativos han sido generalmente considerados antagónicos. Sin embargo, la legitimidad depende de la idea de que la sujeción política se justifica cuando genera bienestar social, aunque esto solo sea operativo a través de un esquema de jerarquización más o menos desigual. ${ }^{1}$

Todos los Estados aspiran a, o ambicionan, suscitar una percepción difundida sobre la equivalencia del Estado como el gestor de un programa, que, en última instancia, está dirigido a favorecer de manera cabal a los diferentes segmentos de la forma social que demarca los linderos de su autoridad. Para sostener esta noción de autoridad legítima, los Estados se involucraron crecientemente en las transformaciones económicas, $y$, una vez vinculados en el proceso de acumulación del capital, la responsabilidad por privaciones económicas no puede ser delegada fácilmente al mercado o a constricciones ambientales.

Así, la legitimidad interna se consigue por la vía de su implicación en los procesos económicos o por la posibilidad de persuadir a los grupos sociales de la maximización del bienestar social a partir de las decisiones estatales. Al involucrarse en dichos procesos, el Estado se inserta en un sistema internacional, no solo como sistema de entidades políticas soberanas, sino como un sistema de división del trabajo. De este modo, la conexión entre el logro doméstico (legitimidad interna) y el contexto externo (integración hacia afuera) se vuelve mucho más cercana y directa (Evans, 1995).

1 Este argumento corresponde a la conexión que gestiona el Estado entre los términos de su inserción en la división internacional del trabajo y el rédito doméstico que consigue con su implicación en la actividad económica (Evans, 1995). 
Por lo anterior, puede considerarse al proceso de expansión y diversificación de la estructura económica (específicamente en sus manifestaciones históricas en el sector agrícola) como campo analítico revelador para observar las operaciones estatales.

Las sociedades en el curso de su existencia tienden a desarrollar una variedad de formas institucionales ${ }^{2}$ diseñadas para promover, controlar o dirigir las fuerzas favorables a los cambios. Las transformaciones vinculadas al proceso económico se orientan a expandir la capacidad, las fuerzas productivas y los medios de subsistencia que una economía puede ofrecer. El desarrollo económico es un proceso de transformaciones históricas orientadas por el esfuerzo de alterar condiciones pasadas y desplazarse hacia un nuevo contexto futuro distinto. Se diferencia del crecimiento económico, aunque suele requerirlo pues supone cierto grado de cambio estructural: algún cambio en los patrones de selección sedimentados que determinan lo que ha de reconocerse como materia de regulación, lo que ha de tematizarse, lo que ha de regularse públicamente, así como las prioridades con que ha de hacerse esto último, y los canales por utilizar. ${ }^{3}$

Estos procesos de transformación son detonados por factores internos y/o externos a la economía nacional y a la actividad económica en sí. Cuando la expansión de las potencialidades productivas requiere replantear la reasignación de recursos, buscar recursos nuevos o incrementar el empleo de productivos ocurre una transformación estructural y puede hablarse de desarrollo económico. ${ }^{4}$

Las transformaciones en la estructura productiva y en los patrones que organizan la división del trabajo se acompañan de un proceso central a la propuesta de este trabajo: el desarrollo financiero. Las finanzas son una actividad factible solo en un entorno de desarrollo económico real y, asimismo, dependiente de las condiciones de la demanda y la oferta de activos financieros. Sobre esta definición integral del desarrollo económico, la transformación técnica y el cambio estructural y la oferta de recursos consecuente, se introduce la reflexión sobre la significación de la transformación tecnológica del sector agrícola en la trayectoria del desarrollo mexicano.

2 Este artículo, siguiendo la definición de Portes (2006), asume que las instituciones deben comprenderse como proyectos de las organizaciones. Las organizaciones se concretan y habitan por actores y son la manifestación más visible de las estructuras de poder que les subyacen. A su vez, las organizaciones se componen de jerarquías de estatus vinculados a roles diferenciados. Los proyectos pueden ser escritos o inmateriales; su propiedad central es la posibilidad de orientar las relaciones entre los ocupantes de roles en las organizaciones sociales como la familia, las escuelas, o en grandes áreas institucionalmente estructuradas de la vida organizacional como la política y la economía. Las instituciones no son estructuras sociales, tienen estructuras sociales (organizaciones) como encarnación de los proyectos que guían las relaciones entre roles.

3 Habermas (1999) diferencia el desarrollo de otros procesos de variación en la economía, delimitando el carácter y el nivel del cambio para que se considere como una transformación estructural. Si el desarrollo se comprende de esta forma debe alterar de alguna manera los fundamentos precedentes.

4 Como parte de las elaboraciones orientadas a distinguir crecimiento de desarrollo y analizar sus implicaciones, una primera asunción se origina en la idea que, cuando se habla de desarrollo, existe algún grado de transformaciones fundamentales. Para determinar si esos cambios son realmente disruptivos, Flammang (1979) propone: (i) atender a criterios históricos concretos e implicaciones diferenciales según el curso del proceso; (ii) identificar diversos detonantes, y, fundamentalmente, (iii) definir escenarios en que podría derivar el proceso para implicar cambios estructurales.

tiempo\&economía

Vol. $3 \mathrm{~N}^{\circ} 1$ - I semestre de 2016 


\section{Fertilizantes y procesos de cambio tecnológico en la agricultura}

La importación regular de guano peruano a Inglaterra desde 1840 rompió la autosuficiencia del sistema productivo agrario europeo al introducir un insumo de fuera del sector y aumentó la dependencia de la agricultura europea del comercio mundial. El creciente consumo de guano se acompañó de avances en la química agraria asociados al análisis químico y la experimentación en campos de cultivo requerida para conocer la calidad de esos abonos. La necesidad de establecer la composición química de los guanos por importar acentuó la importancia de la química para los agricultores y sentó las bases de la producción manufacturera de guanos artificiales y abonos minerales.

Hasta 1870 , las tareas de abonado se repartían entre guanos y abonos orgánicos, mientras que la mayoría de la fertilización nitrogenada recaía en el abono verde. Solo Inglaterra utilizaba grandes cantidades de guano y comenzaba la producción de abonos minerales. Entre 1870 y 1914, el nitrato de sosa irrumpe como abono nitrogenado, se expande el uso de abonos minerales e inicia la fabricación de nitrogenados sintéticos. Inglaterra pierde el control del comercio del nitrato de sosa, y Alemania y Francia asumen la superioridad en la fabricación de abonos minerales. En estos años, la química agraria cobra gran relevancia en círculos académicos, y el comercio de guanos y abonos minerales alcanza gran éxito económico. Ya en el periodo de entreguerras, el consumo de abonos minerales aumenta considerablemente y se consolida el uso del sulfato amónico (Calatayud y Mateu, 1995).

Estos cambios tecnológicos supusieron un aumento de la producción agrícola y llevaron a una preocupación creciente, evidente en las políticas públicas, respecto al impacto de las nuevas tecnologías sobre el empleo agrícola y la distribución del ingreso rural. El cambio tecnológico en la agricultura asociado a esos nuevos abonos transforma la agricultura tradicional basada en el uso de materiales y procesos biológicos naturales en combinación con el trabajo y la gestión humana. Se empieza a consolidar un nuevo esquema de agricultura moderna en la que el conocimiento científico desde innovaciones biológico-químicas permite aumentar la productividad de los cultivos y alcanzar rendimientos crecientes (Timmer, 1988).

El pasaje de un modelo productivo a otro, no obstante, no se da de forma automática. Paulatinamente los nuevos abonos se fueron adaptando y complementando con las prácticas tradicionales de abonado orgánico (Calatayud y Mateu, 1995). Además, las habilidades necesarias que los agricultores requerían para incorporar las nuevas tecnologías en sus métodos productivos dependieron en gran medida del nivel de la inversión gubernamental en servicios de extensión, educación general (educación primaria, con instrucción en habilidades agrícolas) e infraestructura rural, para reducir costos de intercambio y transacción.

Dado que la mayoría de la nueva tecnología agrícola se materializa en un producto físico (una bolsa de fertilizante pero igualmente semillas, maquinaria agrícola o instrumentos de riego nuevos), la eficacia de la tecnología depende de la compra del agricultor. Varias consecuencias se derivan de este simple hecho. Para que pequeños agricultores participen de los beneficios del cambio técnico deben poder comprar el insumo vinculado a la nueva tecnología. Para comprar un nuevo paquete de semillas fertilizantes con una tasa de $200 \%$, les puede ser rentable solicitar un préstamo a nivel local de una tasa de $10 \%$ mensual. Sin embargo, a las familias agrícolas con propiedades menores a media hectárea les resulta central 
contar con sistemas formales de crédito rural. Del mismo modo, en tanto la nueva tecnología se encuentra incorporada en un producto comercial es necesario un sistema de comercialización y distribución que asegure la posibilidad de compra de semillas y fertilizantes a los agricultores, especialmente a los productores más dispersos territorialmente (Timmer, 1988).

\section{Modernización de la agricultura mexicana derivada del cambio tecnológico asociado a la investigación agrícola y la masificación del uso de fertilizantes}

Este proceso de cambio tecnológico agrícola inicia en México en los años cuarenta con un rol clave del Estado. La inversión agrícola en riego iniciada en los años treinta continuó realizando obras en regiones donde se detectaba mayor potencial de crecimiento o cierto nivel de desarrollo. ${ }^{5}$ Esos agricultores de riego recibieron la mayoría de los beneficios de dos procesos iniciados en esta década.

El primer proceso fue el programa de investigación en cultivos de alimentos básicos que crearon en 1943 el gobierno federal y la Fundación Rockefeller. Este programa desarrolló variedades de semillas que respondían a fertilizantes, investigaciones sobre la roya del trigo y mezclas de fertilizantes para distintos cultivos y suelos. Desde 1950 este programa comenzó a dar resultados en cuanto a rendimientos y producción de los principales cultivos (Grabowski y Sánchez, 1987).

El grado de éxito del programa mostró diferencias entre los sistemas agrícolas nacionales más tecnificados y modernos (especialmente en el norte, donde existían más sistemas de riego) y los tradicionales (particularmente, del Altiplano central). El programa fue exitoso en el sector agrícola minoritario compuesto por productores y expertos de clases medias. Este grupo contaba con un sistema productivo más intensivo en capital, orientado al mercado y no a la subsistencia y vinculado a una red de instituciones comerciales y públicas diseñadas para el logro de unidades más eficientes. En cambio, el programa fracasó ante la mayoría del sistema agrícola de productores de subsistencia, intensivo en trabajo y desconectado de cualquier asistencia experta (Fitzgerald, 1986).

El segundo proceso relevante se vinculó a la adopción masiva de abonos minerales, particularmente a partir del impulso de Guanomex, empresa pública creada en 1943. Para Hertford (1967), 77\% del cambio en la producción de cultivos en México desde 1953 debe atribuirse a cambios en sus rendimientos. Del total de cambios de rendimientos en el cultivo, $75 \%$ se asocia a la creciente aplicación de fertilizantes químicos. El uso de fertilizantes crece enormemente en esos años: el consumo crece de 12 mil toneladas en 1950 a 169 mil en 1960 (Puente, 1971), manteniendo un crecimiento promedio anual de 15\% hasta 1979 (Grabowski y Sánchez, 1987). Repitiendo el patrón observado en los beneficios del programa de investigación agrícola nacional, para 1960 el 90\% de fertilizantes eran consumidos por predios superiores a cinco hectáreas, predios más tecnificados y mecanizados que generaban el 54\% de la producción agrícola nacional (Puente, 1971).

5 Los proyectos de irrigación se concentraron en las regiones norte, noroeste y noreste, pues en ellas la irrigación era menos costosa y había expectativas de aumentar el producto agrícola vía riego. Según Gollás (2004), no fue casual que las principales obras de riego se dieron en los estados natales de los más importantes jefes revolucionarios. 


\section{Los antecedentes de la instauración de Guanomex}

El establecimiento de la industria estatal de fertilizantes es parte de un proceso que define varias transformaciones: (i) el pasaje de la agricultura como actividad de subsistencia a la diversificación, tecnificación y expansión productiva; (ii) la incursión, a través de la infraestructura financiera estatal, de una agencia para la asignación y distribución de recursos que marcó el giro hacia la diversificación de la propiedad y la posibilidad de eslabonamientos en el mercado interno, y (iii) el consecuente fortalecimiento institucional de la promoción de actividades estratégicas para el desarrollo económico.

En México, la industrialización como proceso de establecimiento y expansión de la productividad en fábricas a gran escala, con organización y equipamiento moderno, fue iniciada en la administración de Porfirio Díaz (1876-1911). No obstante, el proceso de industrialización desarrollado desde 1890 (incluso del tipo sustitutivo) estuvo disociado de ampliaciones del bienestar o la estructura de accesos (Vargas, 2013).

Este artículo propone que el inicio del proceso de dirección estatal del desarrollo (las acciones que cobraron trascendencia histórica y marcaron la inflexión hacia la transformación estructural) ocurre 42 años después de iniciada la modernización industrial nacional. De igual modo, para este trabajo, la banca de desarrollo industrial como unidad de análisis permite explicar el tipo nacional de organización para el financiamiento del desarrollo económico, en cuanto tipo específico de acción económica estatal.

Estos dos supuestos centrales de este estudio se sustentan en un mismo argumento común: existe una vinculación entre la manera en que: (i) una forma estatal (en el marco de una economía nacional) viabiliza y promueve su programa de expansión o diversificación de la actividad económica y (ii) la estructura industrial asociada a estas iniciativas. Esta relación entre forma estatal y estructura industrial está mediada por la movilización del capital como procedimiento organizacional de la forma estatal. Las agencias de planificación y fomento y el giro en la política económica no originan la industrialización, pero es a través de su operación que reconfiguran el patrón de la estructura productiva.

En nuestro estudio de caso se observa que la gestión estatal de la transmisión de recursos hacia la inversión productiva puede romper los esquemas de privilegios y las barreras de entrada asociados con la industrialización iniciada en el Porfiriato. Cuando la expansión del mercado externo se consiguió a través de la organización productiva del tipo enclave, la reorganización y la intervención de la forma estatal en la economía fueron imperativos. No solo por la fragilidad de la clase industrial nacional, sino porque los nuevos grupos que controlan la infraestructura administrativa del Estado requieren establecer un mecanismo de acumulación rápida de capitales.

El deterioro del segmento vinculado a la economía de enclave fue necesario para que, en cierto grado, nuevos grupos pudieran adecuar y utilizar la forma estatal. Esto es: establecer los medios de acumulación e inversión que viabilizaran un mercado interno con potencialidades que, a su vez, serían sustento y justificación de las nuevas acciones, en tanto aseguraran la disponibilidad de recursos suficientes para reinvertirse en la economía nacional (Vargas, 2013).

La organización estatal del financiamiento al desarrollo es una solución endógena a la incapacidad o el desinterés del sector exportador-importador por generar un régimen de 
acumulación del capital que reditúe en el mercado interno. A través de esta intervención, la forma estatal se reorganiza, y se definen las instancias que deciden sobre la inversión, el consumo y la transferencia del ahorro. ${ }^{6}$

Esta reorganización determinó líneas de desarrollo industrial prioritarias a futuro. Entre estas se ubicaban, en primer lugar las industrias que usaban materias primas de la agricultura doméstica: procesamiento de cereales, preparación de aceites comestibles, producción de azúcar, fabricación de artículos hechos de fibra (algodón, lana, henequén).

También la industria química se calificó como de primera importancia, por cuanto existían en México materias primas para hacerla operativa. Además de su importancia estratégica en cuanto a la activación de toda la economía nacional, la producción de químicos beneficiaría la estructura industrial nacional (como materia prima de muchas manufacturas) y la agricultura (con productos como insecticidas y fertilizantes, que incrementan su productividad).

Finalmente, debe destacarse que este proceso de desarrollo económico también se basó en la promoción público-privada de tres grandes centros de industria pesada (las ciudades de Guadalajara, Monterrey y Ciudad de México), diseñados para cubrir las necesidades de la industria mexicana de energía eléctrica, combustible, químicos, hierro y acero, maquinaria y herramientas (Mosk, 1950).

En el marco de los primeros estudios de promoción a las actividades industriales, y siguiendo el patrón de desarrollo abastecido y tecnificado por recursos y servicios externos, las imágenes 1 y 2 contraponen la visión estatal de Nafin y la privada, desde la compañía de servicios de ingeniería Ford, Bacon \& Davis.

Imagen 1. Visión de Nafin respecto a la importancia de producir fertilizantes

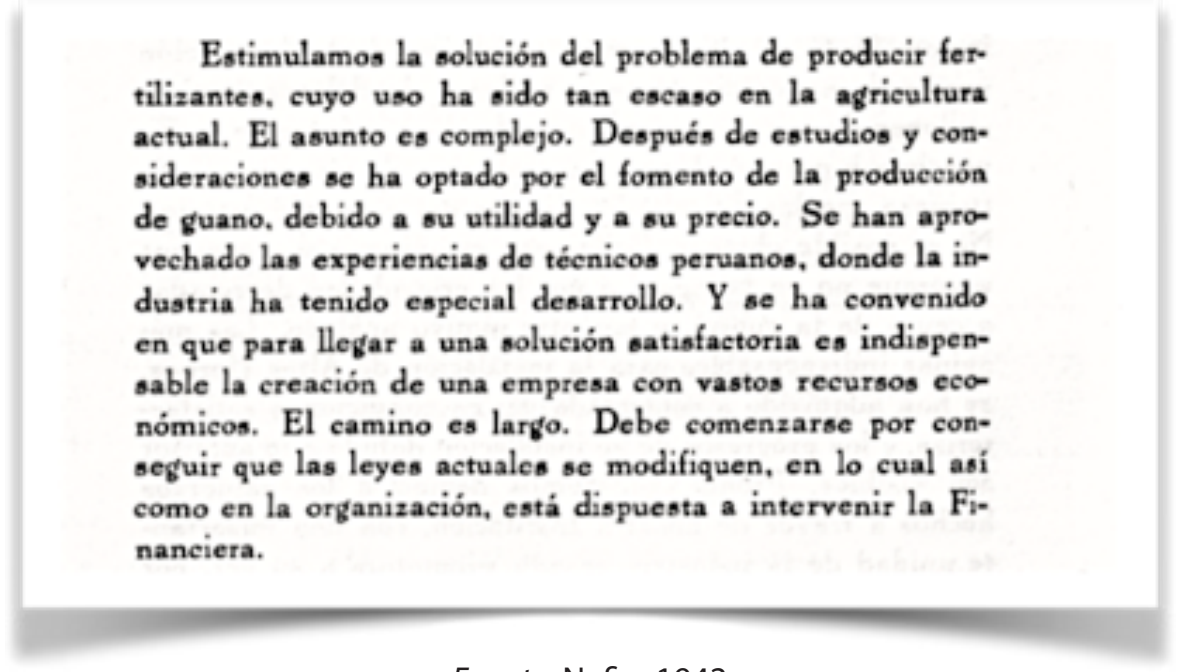

Fuente: Nafin, 1942.

6 Este argumento parte de la concepción desarrollada en los estudios sobre cursos de dependencia y los factores que requiere cierta circunstancia para alterar la trayectoria antecedente y desplazarse hacia formas estructurales que definen el ámbito nacional, la forma estatal y la comunidad económica (Cardoso y Faletto, 1979). 
Imagen 2. Reporte organizacional de la empresa Ford, Bacon \& Davis Incorporated Engineers

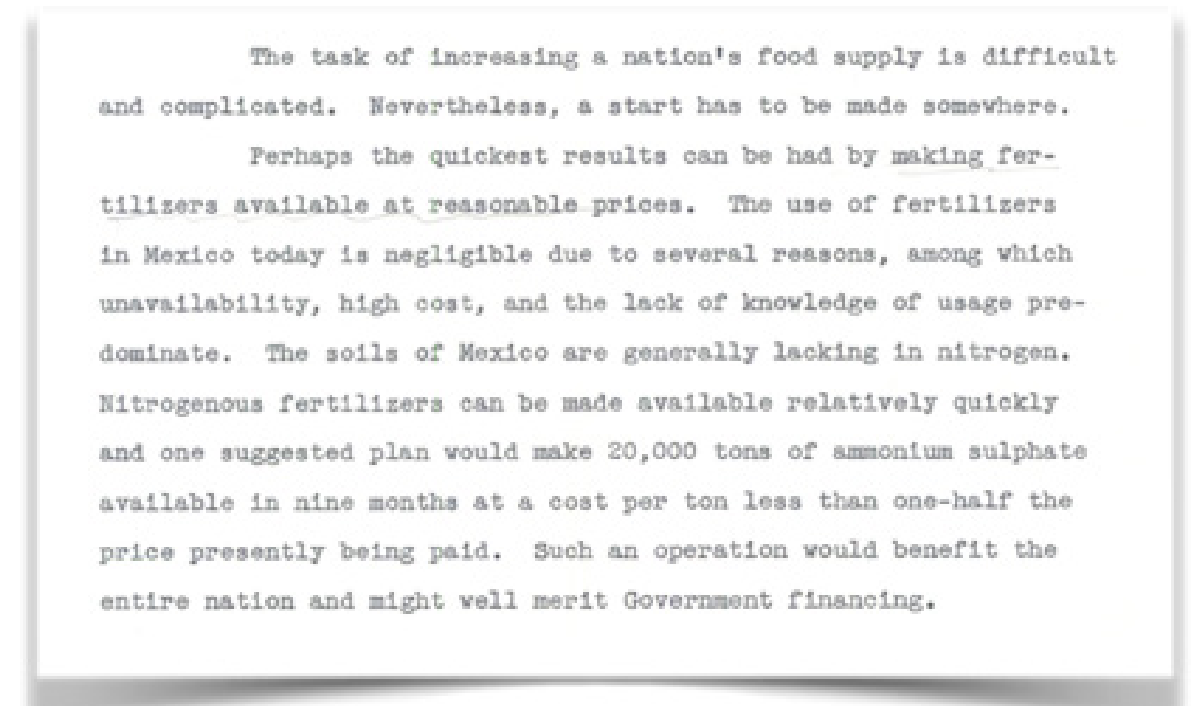

Fuente: Nafin, 1947.

\section{Desarrollo, trayectoria y transformación histórica de Guanos y Fertilizantes de México}

Industrialización, modernización, proteccionismo, subsidios y sustitución de importaciones fueron procesos que, desde la forma estatal y la acción económica porfiriana, se registraron sin implicar posibilidades de un control nacional de la producción y de la acumulación. La forma en que se financiaba la actividad económica hizo estéril cualquier iniciativa estatal por orientar el desarrollo. Tampoco el establecimiento de la banca central del Estado fue detonante del cambio. Fueron la organización, la adaptación, el diagnóstico y la adecuación de la acción financiera del Estado los que alteraron las formas prototípicas de la economía.

El modelo de financiamiento del desarrollo que se conjuga en la banca muestra su rol central para la transformación en la estructura industrial. Esto implicó la reorganización estatal de los procedimientos para reasignar el capital con fines productivos, en un marcado de giro hacia un control nacional de la acumulación y la reordenación productiva.

La centralidad de Guanomex refleja así una formalización de la agricultura industrial y una intervención estatal con dos sentidos: (i) la producción artificial de insumos para el desarrollo del sector y (ii) la canalización institucional de fondos públicos externos para financiar proyectos endógenos autorizados por la agencia crediticia para las exportaciones de bienes de Estados Unidos.

Guanomex se estableció en el centro del país, a 31 kilómetros de Ciudad de México. Inicialmente, la organización de su propiedad correspondía al patrón de otras empresas en la industria básica, que pertenecía en su totalidad a Nafin.

Una propuesta de etapas históricas que incorpora la trayectoria del modelo de propiedad en la industria de fertilizantes, y particularmente de Guanomex, muestra que ese camino también 
se asoció a las aprobaciones crediticias. De 1943 a 1948, la promoción de la industria agroquímica se consiguió por las operaciones de Nafin, sin mayor participación de capital externo hasta que en 1947 se presenta como proyecto al Exim, que aprueba en 1948 un crédito de seis millones de dólares para su expansión. A continuación se detalla una periodización de la empresa y de los agentes y procesos preponderantes en la producción de fertilizantes en México.

\section{Primera etapa: $1943-1946$}

Guanomex se instaura en junio de 1943 como empresa gubernamental descentralizada. Inicialmente tuvo la función de promover la explotación de fertilizantes orgánicos, actividad fundamentada en distintos informes sobre la presencia de depósitos de guano en costas e islas del Pacífico.

La producción estatal de fertilizantes vía Guanomex activó un tipo de intervención orientado por la oferta. La demanda de una empresa creada por la banca de desarrollo no tenía relevancia. La oferta instituida por las agencias financieras del Gobierno fue el factor determinante para impulsar proyectos de desarrollo agrícola desde una infraestructura que asegurara los medios básicos de industrialización nacional. La promoción se hizo manifiesta a través de la propiedad: Nafin fomentaba el establecimiento de empresas que solventaran los cuellos de botella vía producción de insumos agrícolas e industriales (ver la tabla 1). En este marco, Guanomex fue una de las veintisiete empresas creadas por la banca de desarrollo como propietario o principal accionista, durante la fase en que la intervención equivalía a la participación directa de lo que se ha conceptualizado como el Estado Empresario (Nafin, 1943, 1944, 1945 y 1946).

Sin embargo, limitarse a la intervención del tipo-propietario subestimaría la labor de Nafin para la primera fase de la temporalidad del proceso de desarrollo económico en México. Específicamente en la industria fertilizante, Nafin adquiere la función de generador de conocimiento técnico, una labor significativa para identificar y operar la producción artificial de guano ${ }^{7}$ como materia prima de la producción de fertilizantes.

Tabla 1. Datos básicos de industrias impulsadas por Nafin

\begin{tabular}{|c|c|r|r|r|}
\hline \multirow{2}{*}{ Empresas } & \multirow{2}{*}{$\begin{array}{c}\text { Inicio de } \\
\text { operaciones }\end{array}$} & \multicolumn{2}{|c|}{ Producción anual } & \multirow{2}{*}{$\begin{array}{c}\text { Inversiones totales } \\
\text { (miles de pesos) }\end{array}$} \\
\cline { 3 - 5 } & 1941 & $1.200 .000 \mathrm{mts}^{2}$ & 10.003 & 3.700 \\
\hline Chapas y Triplay & 1942 & $\begin{array}{c}420.000 .000 \\
\text { K.W.H. }\end{array}$ & 33.600 & 155.000 \\
\hline Nueva Cia. Eléctrica de Chapala & 1943 & $489.000 \mathrm{~T}$ & 9.200 & 35.000 \\
\hline Carbonífera Unida de Palau & 1943 & $120.000 \mathrm{~T}$ & 12.000 & 17.300 \\
\hline Cementos Guadalajara & 1943 & $120.000 \mathrm{mts}^{3}$ & 5.100 & 6.000 \\
\hline Unión Forestal de Jalisco y Colima & 1943 & $146.000 \mathrm{~T}$ & 75.000 & 113.000 \\
\hline Altos Hornos de México & & & & \\
\hline
\end{tabular}

7 El guano también puede designar al abono mineral fabricado a imitación del guano natural, usualmente con el sobrante de la pesca que no es aprovechable para alimentación, que en las pesquerías tradicionales se utiliza para producir abono. 


\begin{tabular}{|c|c|c|r|r|}
\hline $\begin{array}{c}\text { Guanomex (incluye planta de sulfato } \\
\text { de amonio) }\end{array}$ & 1943 & $20.000 \mathrm{~T}$ & 6.000 & 18.800 \\
\hline Empacadoras Calidad & 1945 & 2.000 .000 latas & 4.000 & 5.800 \\
\hline Cementos Portland del Bajío & 1946 & $120.000 \mathrm{~T}$ & 12.000 & 26.000 \\
\hline Cobre de México & 1946 & $12.000 \mathrm{~T}$ & 30.000 & 7.250 \\
\hline Aceros Esmaltados & 1946 & 28.000 estrías & 10.000 & 5.000 \\
\hline Cia. Industrial de Atenquique & 1946 & $39.000 \mathrm{~T}$ & 3.000 & 57.000 \\
\hline
\end{tabular}

Fuente: Nafin, 1949b.

Al igual que la mayoría de la industria orientada al mercado interno en México, la producción de fertilizantes inicia por la intervención financiera del Estado como propietario de empresas. Esta actividad, que comienza con la inflexión de inicios de la década de 1930, se hace operativa durante los años cuarenta con la creación de la empresa estatal para la producción de fertilizantes.

\section{Segunda etapa: expansión de la empresa pública y relaciones Exim-Nafin (1947-1953)}

La promoción de Nafin como accionista de diferentes empresas logró, paulatinamente, generar una pauta de distribución territorial de los recursos que canalizaba. En estos años, Nafin amplía la estructura geográfica de la actividad económica, antes excesivamente concentrada en los estados del norte del país, con mayores niveles de industrialización que las regiones centro-sur, y donde se ubicaban capitales asociadas al modelo de crecimiento de fines del siglo XIX (ver la imagen 3).

Imagen 3. Distribución geográfica de las empresas promovidas por Nafin para 1949

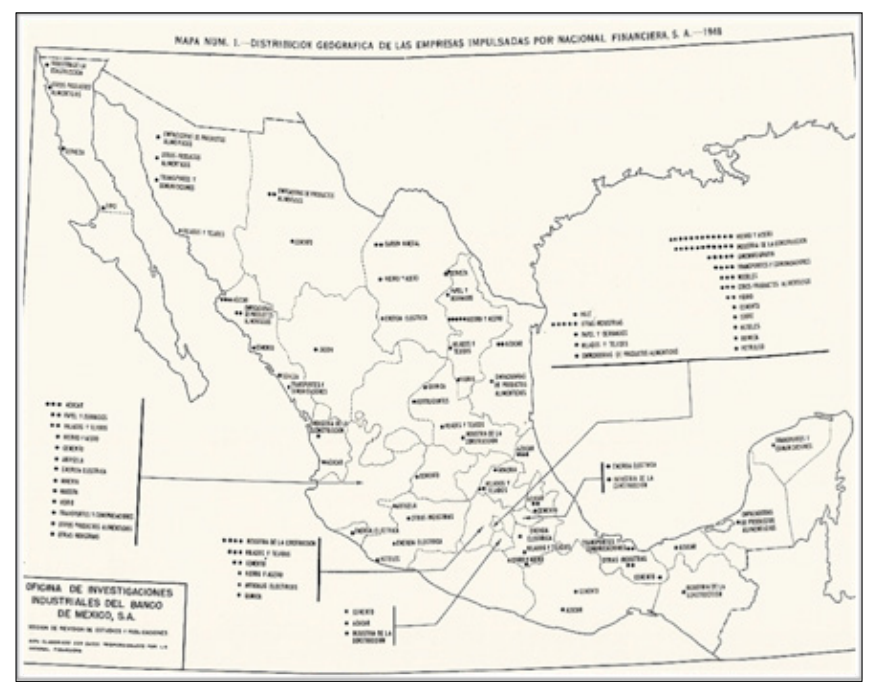

Fuente: Carrillo, 1950.

En 1947, Exim aprueba a Nafin la asignación de 33,5 millones de dólares para la financiación de distintos proyectos productivos (ver la tabla 2). 
Tabla 2. Autorizaciones de crédito de Exim a Nafin (1947 y 1948)

\begin{tabular}{|c|c|c|}
\hline Fecha & Monto (dólares) & Destino \\
\hline Abril 1947 & 16.500 .000 & Equipos, instalaciones y servicios de EE. UU. \\
\hline Octubre 1947 & 3.500 .000 & $\begin{array}{c}\text { Materiales, equipos y servicios para el proyecto hidroeléctrico de Colimilla - } \\
\text { Nueva Compañía Eléctrica de Chapala. }\end{array}$ \\
\hline Noviembre 1947 & 5.000 .000 & Equipo agrícola \\
\hline Diciembre 1947 & 1.000 .000 & Equipo para planta empacadora de carnes \\
\hline Diciembre 1947 & 12.000 .000 & Materiales y equipos para la construcción de la carretera de la Costa Occidental \\
\hline Diciembre 1947 & 7.000 .000 & Equipo ferroviario \\
\hline Diciembre 1947 & 5.000 .000 & Materiales y equipos para planta de sulfato de amonio \\
\hline Febrero 1948 & 6.000 .000 & \\
\hline
\end{tabular}

Fuente: Nafin, 1947, 1948 y 1949

Entre estos proyectos financiados por Exim destaca el relacionado con el préstamo otorgado en 1948 a la planta de fertilizantes nitrogenados y amoniaco de Guanomex (ver la imagen 4) en Cuautitlán (cercano a la ciudad de México). Esta era una planta moderna (la primera de su tipo en México) que utilizaba gas natural transportado desde el golfo de México. La ingeniería, los servicios de diseño, la supervisión de la construcción y las operaciones iniciales son realizados por la empresa estadounidense Chemical Construction Corporation. La nueva planta supuso un paso significativo hacia la automatización productiva como estrategia ante la escasez de mano de obra calificada en México (Nafin, 1949 y 1950).

Imagen 4. Memorándum al Consejo de Directores de Exim respecto al préstamo para la nueva planta de Guanomex

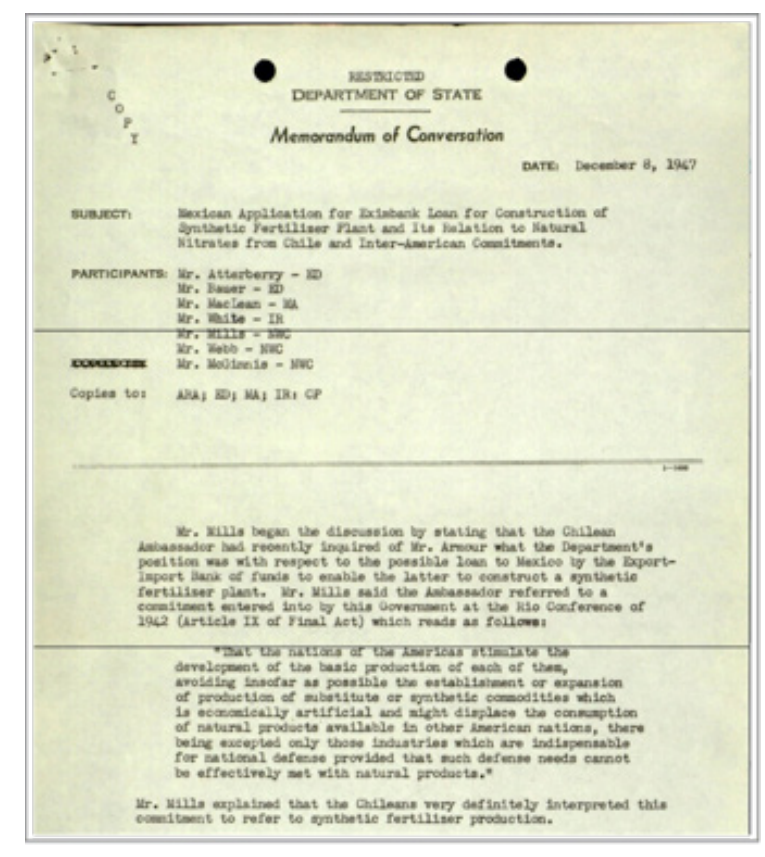

Fuente: NACP, 1948.

tiempo\&economía

Vol. $3 \mathrm{~N}^{\circ} 1$ - I semestre de 2016

p. 73 
La autorización de los préstamos de Exim a Nafin en 1947 no estuvo exenta de confrontaciones. Varios asesores del comercio exterior estadounidense se oponen, no a todo el programa de asignaciones, pero sí al menos a la financiación de ingenios azucareros, considerada una asignación para la producción de excedente (Nafin, 1948).

Además, otras dos controversias se suman al debate frente a la línea de créditos de 1947. La primera se relaciona con la producción sintética de fertilizantes nitrogenados subvencionada por el Exim en México. Como puede verse en la imagen 5, la reacción en este caso viene del Gobierno chileno, que argumenta que el proyecto relacionado con los fertilizantes nitrogenados viola uno de los acuerdos del comercio hemisférico.

Imagen 5. Referencia de Exim a la oposición chilena al proyecto, fundamentada en acuerdos que dan preferencia a la extracción de recursos naturales sobre la fabricación de similares sintéticos

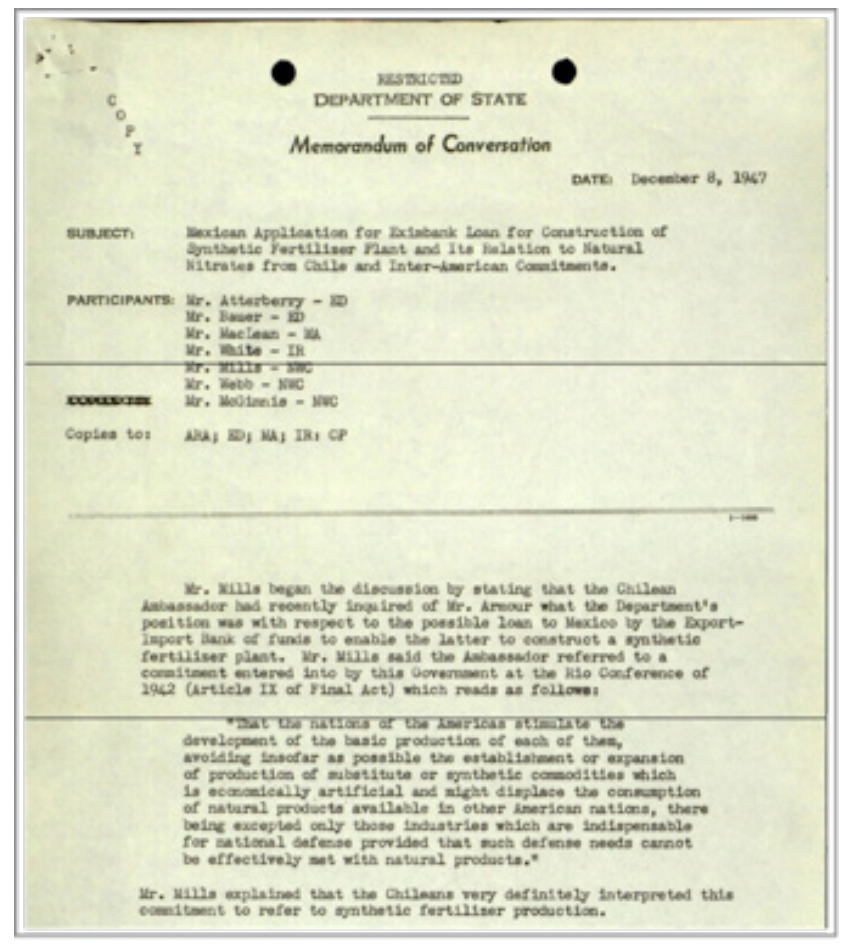

Fuente: NACP, 1947.

Hacia finales de 1950 se completan diferentes proyectos de desarrollo que Exim financia en México. El segundo reporte semestral de Exim de ese año reconoce oficialmente el progreso de la economía mexicana y los planes del Gobierno de continuidad al desarrollo. Esto se convierte en la justificación por la cual la Junta de Exim decide extender un compromiso por 150 millones de dólares para préstamos futuros vía Nafin, orientados al desarrollo económico de México en proyectos de transporte ferroviario y carreteras, agricultura e irrigación, comunicaciones y generación y transmisión de energía eléctrica (NACP, 1946, 1947, 1948, 1949 y 1950). 
El compromiso establecido sigue el patrón exitoso iniciado con los préstamos autorizados en 1947, donde ambas agencias coinciden en que todos los recursos se asignarían a proyectos de expansión productiva. Desde el primer préstamo a México, autorizado por Exim en 1935, y hasta finales del año 1950, Exim otorga préstamos por 135,9 millones de dólares, de los cuales Nafin reembolsó 55,9 millones. Esto ubica a México como uno de los principales clientes de Exim.

En relación con Guanomex, en 1948 un decreto presidencial amplía su actividad a la producción y distribución de fertilizantes químicos. En 1949, por su parte, se construyen instalaciones para la producción de superfosfato sencillo en San Luis Potosí. En términos de capacidad productiva de la industria química, para 1953, y pese a los notables incrementos de producción de abonos químicos y orgánicos, se observa una demanda de fertilizantes aún mayor a la oferta del sector nacional (Nafin, 1949, 1954 y 1955).

Tabla 3. Producción de fertilizantes en México 1941-1953 (en toneladas)

\begin{tabular}{|c|c|c|c|}
\hline Año & Abonos químicos & Abonos orgánicos & Fórmulas \\
\hline 1941 & 6.300 & 4.600 & 12.500 \\
\hline 1942 & 6.600 & 5.000 & 16.000 \\
\hline 1943 & 7.400 & 5.950 & 19.500 \\
\hline 1944 & 7.800 & 6.350 & 20.800 \\
\hline 1945 & 7.500 & 7.550 & 20.200 \\
\hline 1946 & 7.100 & 8.800 & 24.900 \\
\hline 1947 & 16.690 & 8.750 & 22.500 \\
\hline 1948 & 14.415 & 8.242 & 3.500 \\
\hline 1949 & 19.229 & 8.075 & 36.000 \\
\hline 1950 & 18.462 & 10.220 & 38.000 \\
\hline 1951 & 52.967 & 11.088 & 40.000 \\
\hline 1952 & 116.000 & 21.500 & sin datos \\
\hline 1953 & 127.200 & 36.337 & 25.000 \\
\hline
\end{tabular}

Fuente: Nafin, 1942-1954.

Para 1953, los principales problemas de la producción de fertilizantes en México están relacionados con los altos requisitos de inversión requeridos por unidad de producción (especialmente de sulfato de amonio y superfosfatos) y para el abastecimiento de materias primas (ver la tabla 3$)^{8}$.

8 La cuestión de las materias primas es muy sensible, por cuanto la producción dependía de la importación de roca fosfórica (altamente costosa para desarrollarse en México) y de sales de potasio. La producción de amoníaco sigue siendo para esa fecha insuficiente para satisfacer la demanda, mientras que el ácido nítrico se obtenía solo en cantidades pequeñas, por cuanto su elaboración dependía de la costosa importación de nitratos de sodio chilenos (Nafin, 1953b y 1954). 


\section{Tercera etapa: desarrollo de la iniciativa privada en la industria fertilizante (1954- 1964)}

Tras la devaluación de 1954 se instaura una Comisión Especial de Financiamientos Exteriores como organismo consultivo sobre la temática de la deuda del sector público con el exterior, el servicio de dicha deuda y la capacidad nacional de pago en la contratación de nuevos endeudamientos.

Este año, Nafin inicia una modalidad de financiamiento a ciertos sectores y actividades con acceso deficiente a recursos financieros. El financiamiento a través de fideicomisos presenta dos contradicciones para la operatividad de un banco de desarrollo con las características de Nacional Financiera. En primer lugar, Nafin solo ejecuta los fondos (ver la tabla 4), sin injerencia significativa en los determinantes de la asignación. En segundo lugar, la pauta de establecer un fideicomiso para que lo administrara Nafin, casi por cada grupo o subsector económico, inhibe cualquier posibilidad de coordinación, y mucho menos de planeación (Nafin, 1955).

Tabla 4. Fondos y fideicomisos ejecutados por Nafin, 1953-1975

\begin{tabular}{|c|c|}
\hline Año de creación & Descripción \\
\hline 1953 & Fogain (industria mediana y pequeña) \\
\hline 1961 & Pronaf (Programa Nacional Fronterizo) \\
\hline 1962 & Fonep (pequeña y mediana minería) \\
\hline 1967 & Fifonafe (fomento ejidal) \\
\hline 1970 & Fidein (parques industriales y centros comerciales) \\
\hline 1972 & Fomin (fomento industrial, canalización de recursos de capital de riesgo) \\
\hline 1972 & Fenol (equipamiento industrial) \\
\hline 1974 & Fonep (estudios y proyectos) \\
\hline & Fonatur (fomento del turismo) \\
\hline 1974 & Minerales no metálicos \\
\hline 1975 & Ingenios azucareros \\
\hline
\end{tabular}

Fuente: Nafin, 1976.

Desde fines de la década de 1950, el Gobierno mexicano promueve la inversión privada en la industria agroquímica como complemento a las actividades de Guanomex. En particular, Fertilizantes de Monclova S.A. (nitrato de amonio y ácido fosfórico y nítrico), Fertilizantes del Istmo S.A. (nitrato de amonio, urea y ácido fosfórico) y Fertilizantes del Bajío S.A. (urea) se convierten en importantes productores de fertilizantes (Nafin, 1958, 1959, 1960 y 1961).

En 1961 ya se hace manifiesto el cambio en la organización de la propiedad en Guanomex. La industria de fertilizantes se diversifica con empresas como Fertilizantes del Bajío, Fertilizantes de Monclova y Fertilizantes Fosfatados de México. El caso específico de Fertilizantes del Bajío es indicativo del giro en el patrón de financiamiento a la industria agroquímica en México. El canal institucional fundado a través de la intermediación de Nafin para las autorizaciones de Exim se diversifica. El Exim, aunque sigue dando apoyos de manera directa vía Nafin, comienza 
desde estos años a operar sus préstamos vía financieras privadas. En este caso, la Sociedad Mexicana de Crédito Industrial (banca financiera privada), que se encargó de operar créditos autorizados a la empresa Fertilizantes del Bajío (Nafin, 1962).

Así, aunque Exim continúa siendo la fuente de recursos más significativa para el desarrollo de la industria agroquímica nacional, termina la canalización institucional a través de la banca de desarrollo estatal. Esta coyuntura muestra un giro en la periodización de la organización de la propiedad y el financiamiento a los fertilizantes. El año 1954 marca el inicio de una trayectoria de modificaciones en la función de la banca de financiamiento al desarrollo que, en 1974, terminaría en la desarticulación del tipo de organización estatal del financiamiento al desarrollo que significó Nafin (Cárdenas et al., 2003).

Esta transformación implicó una disminución de la autonomía estatal para planificar la distribución y asignación de fondos de la industria agroquímica en México. Tal como se señaló en la introducción de este artículo, la centralidad de la intervención financiera estatal en el desarrollo industrial de la economía nacional fue el factor que (guiado por la oferta) posibilitó la movilización de capital hacia estos rubros. Así como cambia la estructura y composición del sector agroquímico en México, también varía la trascendencia de la intervención estatal en la promoción y planeación productiva y el comercio de fertilizantes como materias primas de la agricultura nacional.

\section{Cuarta etapa: renacionalización durante los años setenta a través de Fertimex y ocaso de Nafin como agencia financiadora del desarrollo industrial (1965-1974)}

La industria fertilizante se reintegra desde mediados de los años sesenta. Entre 1965 y 1969, Guanomex compra varias empresas: Fertilizantes de Monclova, Fertilizantes del Istmo, Fertilizantes del Bajío, Fertilizantes Delta y Montrose Mexicana y Lerma Industrial. Asimismo, el Gobierno transfiere a Guanomex los activos de Industria Petroquímica Nacional, una pequeña empresa privada (Nafin, 1966-1970; Clouthier, 1983). Finalmente en 1970, Guanomex adquiere una participación mayoritaria en Fertilizantes del Istmo Centroamericano (Fertica), sociedad propietaria de plantas de fertilizantes en Costa Rica, El Salvador y Guatemala (White, 1977).

En 1977, el Estado vuelve a renacionalizar la industria de fertilizantes con la creación de la empresa Fertilizantes de México (Fertimex), sustituta de Guanomex, y finalmente fue vendida al capital privado en 1992. Sin embargo, la lógica de esta transformación se ubica en condiciones muy diferentes al contexto de la fundación de Guanomex. Desde 1974, la banca de desarrollo se desmonta, dejando de ser el canal institucional central para el financiamiento industrial. Para el sector agroquímico esto supone la pérdida de centralidad de la banca estatal de desarrollo como instancia determinante de la implicación entre el sector agrícola y la plataforma estatal.

El fin de la forma particular en que se vincularon Estado y sector agrícola, al menos por dos décadas, da cuenta de una redefinición en los términos de financiación, promoción y planeación de la industria agroquímica nacional. En 1974 se reforma la banca estatal de desarrollo económico, cambiando sus roles distintivos, que venía asumiendo formalmente desde 1940 (Nafin, 1987). 
Esta reforma a la banca nacional de desarrollo se apoya en un diagnóstico gubernamental que entiende que México debía iniciar una nueva etapa de industrialización y desarrollo readecuando sus sistemas financieros y de fomento (Nafin, 1987 y 1994) a través de: (i) un giro en las funciones de la banca de desarrollo hacia funciones de banca múltiple (depósito, hipoteca y ahorro); (ii) una descentralización de servicios financieros, y (iii) una priorización al desarrollo de la pequeña y mediana empresas.

\section{Conclusiones}

El argumento central de este artículo ha enfatizado la forma novedosa en que se planteó el vínculo agricultura-Estado desde un canal institucional que ligó entre sí diversas formas de intervención.

En primer lugar, un tipo de intervención que ejecutó la promoción al desarrollo desde la propiedad de las empresas. En segundo lugar, una variedad de financiamiento público iniciado en 1932, desplegado notablemente en la década de 1940 y al menos hasta 1954, y de importancia decisiva hasta 1974. En tercer lugar, una iniciativa transversal a los mandatos presidenciales de aumentar la productividad agrícola asignada a la banca de desarrollo. En cuarto lugar, una coordinación institucional por la cual la banca de desarrollo se reorganiza y establece el Departamento de Promoción, encargado de estudios y negociaciones para encauzar el capital nacional y extranjero al desarrollo de la industria. Y en quinto lugar, la incorporación en el repertorio financiero nacional de arreglos para conseguir crédito público externo, que redefine las funciones de las agencias públicas de fomento e impacta la estructura productiva y sus patrones de especialización. A su vez, la magnitud del recurso público externo y la regularidad en su canalización entraron a formar parte de modalidades nacionalmente diferenciadas para el financiamiento productivo.

La manera en que una forma estatal viabiliza y financia su desarrollo como elemento característico de la estructura económica nacional es un factor distintivo para diferenciar crecimiento y desarrollo económico. En el caso mexicano, la movilización de recursos coordinada por el Estado implicó la inflexión del proceso. El desarrollo económico, como proceso en el que se inserta la trayectoria de la industria fertilizante, no tiene una temporalidad homogénea.

El desenvolvimiento de diferentes factores se genera en momentos diversos: el fomento y la promoción de la industria agroquímica no son simultáneos a los aprendizajes técnicos endógenos sobre la materia. De hecho, el patrón de promoción a estas empresas —apoyado en la compra de ingeniería, maquinaria y equipos extranjeros con créditos para la importación de bienes de capital de Estados Unidos- permitió el rápido desarrollo inicial de la industria pero no se acompañó de procesos de aprendizaje tecnológico como estrategia competitiva que sustentara un proceso nacional de desarrollo económico-productivo.

Como se señaló previamente, toda nueva tecnología agrícola se materializa en un producto físico (bolsa de fertilizante, semillas, maquinaria, instrumentos de riego) cuya eficacia depende de la compra del agricultor. Esto pone un factor crítico en la movilización de recursos para los productores. Resuelto el financiamiento productivo, el factor problemático no atendido en 
el estudio de caso de Guanomex es el del aprendizaje de la nueva tecnología agrícola por el aparato productivo nacional.

Ante el insuficiente mercado de capitales para el desarrollo de la industria de fertilizantes en México, el Estado apuesta por Nafin como canal institucional del financiamiento exterior al desarrollo. Este canal institucional marcó por muchos años la pauta sectorial de industrialización nacional. Pauta que implicaba también un espacio restringido para el desarrollo de capacidades y aprendizajes a nivel nacional. Como los créditos se otorgan para adquirir bienes de capital y servicios de ingeniería de Estados Unidos, las plantas productivas instaladas, expandidas y/o modernizadas estuvieron desacopladas de las capacidades tecnológicas del sector a nivel nacional. Este caso marca la impronta del desarrollo de los años de sustitución de importaciones en toda la región: escasa importancia otorgada a la construcción endógena de capacidades técnicas y sobrevaloración de la relevancia de un proteccionismo nacional frívolo (Fajnzylber, 1983).

Al atender a las condiciones de los créditos de Exim en la etapa de expansión, la vinculación institucional establecida a inicios de los años cuarenta aparece como sin precedentes. La asociación Exim-Nafin permitió a la banca de desarrollo captar recursos sustanciales, a largo plazo y en condiciones favorables, que se tradujeron en numerosos proyectos de infraestructura e industria básica. Por su parte, Exim se implicó en los sectores apoyados desde la siguiente racionalidad: asegurar importaciones esenciales para la economía estadounidense y, simultáneamente, promover y facilitar la exportación de bienes y servicios producidos en Estados Unidos desde un tipo de créditos condicionados, con base en recursos que pueden ocuparse solo para ciertos mercados y productos (Green, 1971). La imagen 6 ejemplifica los términos y condiciones de estos vínculos en el caso de Guanomex.

Imagen 6. Condiciones de un crédito de Exim a Nafin para el desarrollo de Guanomex

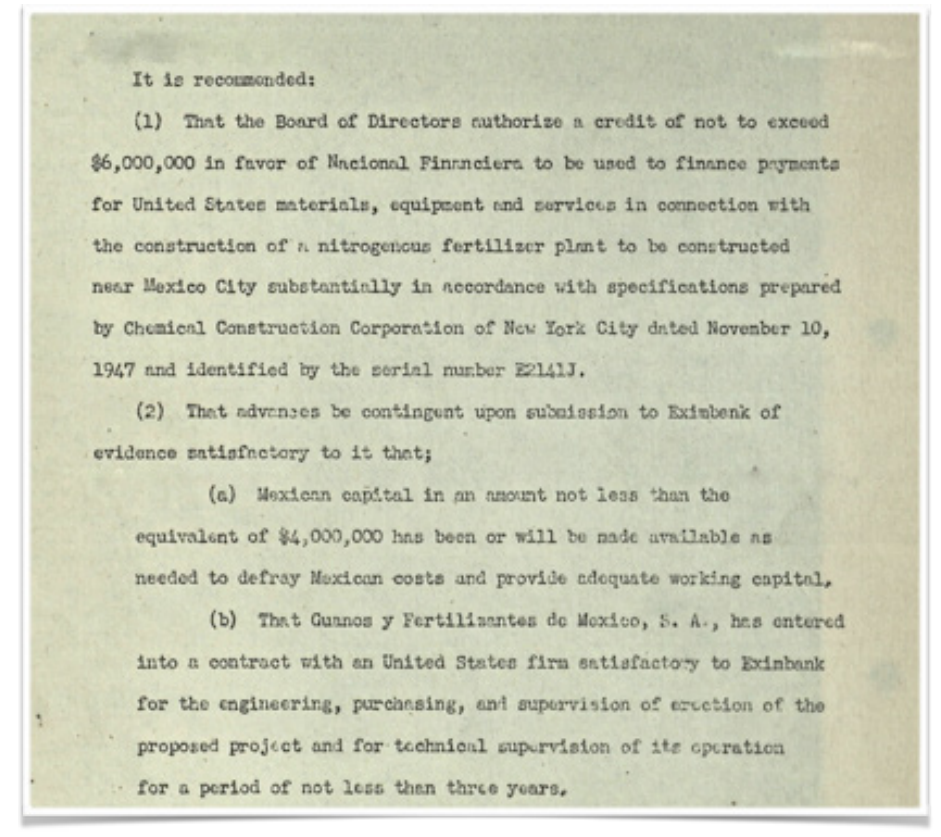

Fuente: NACP, 1948.

tiempo\&economía

Vol. $3 \mathrm{~N}^{\circ} 1$ - I semestre de 2016 
El esquema de vinculación productivo del tipo enclave con el capital extranjero refleja un control nacional en la producción y acumulación. Sin embargo, y como se ha ilustrado a lo largo de este artículo, en términos concretos esta relación supone que el curso del desarrollo siga dependiendo de los imperativos y condiciones establecidos por la economía acreedora.

La temporalidad del desarrollo económico que inicia como proceso orientado por la oferta activa y diversifica la estructura de propiedad y el eslabonamiento sectorial. Pero, a causa del mismo patrón de promoción pública del desarrollo (fundamentada en la adquisición de servicios de ingeniería y bienes de capital extranjeros), la capacidad nacional de generar conocimiento endógenamente resulta inoperativa.

El financiamiento aparece, desde esta perspectiva, como un factor necesario y determinante para el establecimiento de la industria generada por la oferta, pero insuficiente para asegurar una adecuación actualizada de la demanda. Esto lleva a que la distribución y el acceso a estos bienes se vuelvan a articular de forma concentrada y excluyente. El crédito (su coordinación, control, regulación, y los criterios de asignación nacionalmente fundamentados) pierde eficacia como medio para estimular y orientar la estructura de una economía desarrollada por la conducción estatal. Los controles selectivos de crédito no consiguen fomentar una orientación estratégica de la inversión, y con la conformación de grupos financiero-industriales se genera un requerimiento poco significativo del financiamiento al desarrollo industrial vía créditos.

\section{Referencias}

Calatayud, S. y Mateu, E. (1995). Tecnología y conocimientos prácticos en la agricultura valenciana (1840-1914). Noticiario de Historia Agraria, 9, 43-67.

Cárdenas, E., Ocampo, J. y Thorp, R. (2003). Industrialización y Estado en la América Latina: la leyenda negra de la posguerra. México: FCE.

Cardoso, F. y Faletto, E. (1979). Dependency and development in Latin America. Berkeley: University of California Press.

Carrillo Flores, A. (1950). Prácticas, métodos y problemas del financiamiento del desarrollo económico de México. Serie Problemas agrícolas e industriales de México, I, II. México: Talleres Gráficos de la Nación.

Clouthier, M. (1983). La industria paraestatal de fertilizantes. En Instituto Nacional de Administración Pública (ed.), Memoria del Foro de Consulta Popular para la Planeación de la Empresa Pública. México: Inap, 761-780

Evans, P. (1995). Embedded autonomy: States and industrial transformation. Princeton: Princeton University Press.

Fajnzylber, F. (1983). La industrialización trunca de América Latina. México: Nueva Imagen.

Fitzgerald, D. (1986). Exporting American agriculture: The Rockefeller Foundation in Mexico, 1943-53. Social Studies of Science, 16(3), 457-483. 
Flammang, R. (1979). Economic growth and economic development: Counterparts or competitors? Economic Development and Cultural Change, 28(1), 47-61.

Gollás, M. (2004). Auge y ocaso de la agricultura en México. Documento de Trabajo del Colegio de México número 4. México, Colmex.

Grabowski, R. y Sánchez, O. (1987). Technological change in Mexican agriculture: 1950-1979. Social and Economic Studies, 36(2), 187-205.

Green, M. (1971). Inversión extranjera, ayuda y dependencia en América Latina. Foro Internacional 12, 1(45), 1-26.

Habermas, J. (1999). Problemas de legitimación en el capitalismo tardío. Madrid: Cátedra.

Hertford, R. (1967). The development of Mexican agriculture: A skeleton specification. Journal of Farm Economics, 49(5), 1171-1181.

Mosk, S. (1950). Industrial revolution in Mexico. Berkeley: University of California Press.

National Archives at College Park (NACP) —archivos federales de Estados Unidos- (1946, 1947, 1948, 1949 y 1950). Memorandos a la junta directiva del Export Import Bank elaborados por sus asesores respecto a solicitudes de Nafin, Nacional Archives, College Park, Maryland.

Nacional Financiera S.A. (Nafin) (1942, 1943, 1944, 1945, 1946, 1947, 1948, 1949a, 1950, 1951, 1952, 1953a, 1954, 1955, 1958, 1959, 1960, 1961, 1962, 1966, 1967, 1968, 1969 у 1970). Informes anuales. México: Nafin.

Nacional Financiera S.A. (Nafin) (1949b). Quince años de vida de la Nacional Financiera, S.A., 1934-1949. México: Nafin.

Nacional Financiera S.A. (Nafin) (1953b). El desarrollo económico de México y su capacidad para absorber capital del exterior. México: Nafin.

Nacional Financiera S.A. (Nafin) (1987). Nacional Financiera: legislación constitutiva y leyes orgánicas, 1934-1986. México: Nafin.

Nacional Financiera S.A. (Nafin) (1994). Nacional Financiera antes del siglo XXI: el pensamiento de sus directores generales: LX aniversario de Nacional Financiera, 1934-1994. México: Nafin.

Patrick, H. (1966). Financial development and economic growth in underdeveloped countries. Economic Development and Cultural Change, 14(2), 174-189.

Portes, A. (2006). Institutions and development: A conceptual reanalysis. Population and Development Review, 32(2), 233-262.

Puente, J. (1971). Recursos y crecimiento del sector agropecuario en México, 1930-1967. El Trimestre Económico, 38(150), 515-552.

Timmer, P. (1988). The agricultural transformation. En H. Cheeneri y T. Srinivasan (eds.), Handbook of Development Economics (pp. 275-328). Nueva York: Elsevier.

Vargas, N. (2013). La explicación nacional de la acción económica estatal: hacia una sociología histórica sobre los orígenes del tipo estatal de financiamiento al desarrollo. México 1932: el caso de Nacional Financiera. México: El Colegio de México. 
82 Modelos de financiamiento al desarrollo para la industrialización del sector agrícola. El caso de la industria agroquímica en ...

Weber, M. (2003) [1905]. La ética protestante y el espíritu del capitalismo. México: Fondo de Cultura Económica.

White, E. (1977). A ação internacional das empresas públicas na América Latina. Revista de administração, 11(1), 5-64. 